\title{
Pleuropulmonary Blastoma: Case Report
}

A.Tadesse, MD, Philipos Kidane MD1, Birhanu Nega, MD¹, Jakob Schneider, MD², 1Department of Surgery, School of medicine, College of Heath Sciences, Addis Ababa University 2Department of Pathology, School of Medicine, College of Health Sciences, Addis Ababa University

Pleuropulmonary blastoma (PPB) is a rare and aggressive tumor that is emerging as a distinct entity of early childhood disease. It is characterized by mesenchymal elements (including undifferentiated blastoma and often cartilaginous, rhabdomyoblastic, or fibroblastic differentiation) and epithelium-lined spaces. The tumor arises in the lung and pleura and is regarded as a pulmonary dysontogenetic or embryonic neoplasm. It is the pulmonary analog of other tumors of childhood including Wilms' tumor, Neuroblastoma, Hepatoblastoma, Pancreatoblastoma and Retinoblastoma. Due to their protean presentation it is often difficult to make a preoperative diagnosis. A high index of suspicion therefore is needed. As a result these are diagnosed late, and these, along with other factors, affect the eventual outcome. We report a case of Pleuropulmonary blastoma diagnosed after the child was operated as a case of massive left hemothorax following blunt trauma.

\section{Introduction}

Pleuropulmonary blastoma (PPB) is a rare and highly aggressive intrathoracic malignancy in childhood and less than 100 cases have been reported in the literature. In 1961, Spencer first used the term and suggested that PPB arose from mesodermal blastoma because of its similarities to nephroblastoma. In the year1988, Manivel et al. described PPB in children as an entity that was distinct from the biphasic epithelial stromal morphology of the classic adult type. Unlike pulmonary blastoma, PPB lacks the malignant epithelial component and entirely consists of primitive blastoma showing varying levels of sarcomatous differentiation $(1,2)$.We present here a case of this rare tumor.

\section{Case Report}

A three and a half years old female child, the $3^{\text {rd }}$ child and a twin, was presented to our hospital with the complaint of left sided chest pain and shortness of breath of 3 weeks duration following a fall accident while playing and was treated in one of the rural hospitals as a case of community acquired pneumonia and later on chest tube insertion revealed hemorrhagic effusion and was subsequently referred to our hospital. On presentation she was in respiratory distress with RR of 55/min, PR of $144 / \mathrm{min}, \mathrm{Spo}_{2}$ of $68 \%$ with Atm $\mathrm{O}_{2}$ and standard weight and height for her age. Chest examination revealed respiratory distress with subcostal and intercostal retractions, tracheal shift to the right side, and absent air entry with dullness on the left side. Initial labs revealed WBC of 14,100 (71.7\% neut), HCT of $22.8 \%$ and $\mathrm{Hgb}$. of $8.8 \mathrm{gm} / \mathrm{dl}$, ESR of $85 \mathrm{~mm} / \mathrm{hr}$, RBS of $108 \mathrm{gm} / \mathrm{dl}$ and normal RFT. Pleural tap revealed frank blood and chest $\mathrm{x}$-ray (fig.1)revealed massive left pleural effusion with shift of the mediastinum to the right and with the assessment of left massive haemothorax and possibly empyema she was admitted, put on IV antibiotics and left chest tube inserted and clotted blood came out, transfused with whole blood and HCT rose to $36 \%$. The patient was operated through left thoracotomy and severely lacerated left lung with a solid tumor between the upper and lower lobes with massive clotted haemothorax found and hematoma evacuated, left lung removed en block with the tumor, chest tube placed and chest cavity closed. The patient was subsequently discharged improved on her 
$18^{\text {th }}$ postoperative day. Unfortunately she returned back two weeks after discharge with a fungating and infected mass on the previous surgical incision site with empyema and sepsis treated in the hospital with IV antibiotics and chest drain producing thick organized pus and succumbed after one week of stay in the hospital.

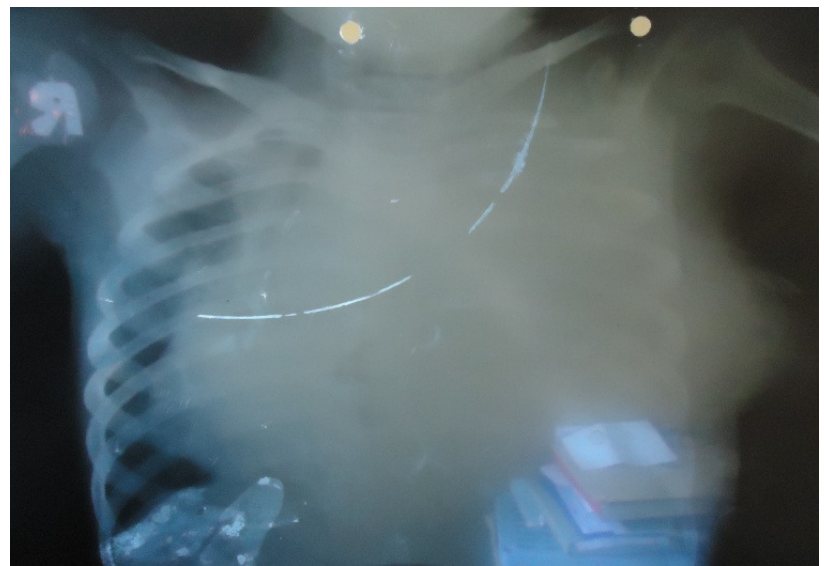

Figure 1. Chest $x$-ray of the child after recurrence of the tumor on the chest wall( arrow)

\section{Pathologic findings}

\section{Gross Appearance}

Lung tissue (2 lobes) with a $5 \mathrm{~cm}$ mass attached to the lung by a stalk. Cut surface: gray white solid, surrounded by a small rim of lung parenchyma, invasive border. (fig 2).

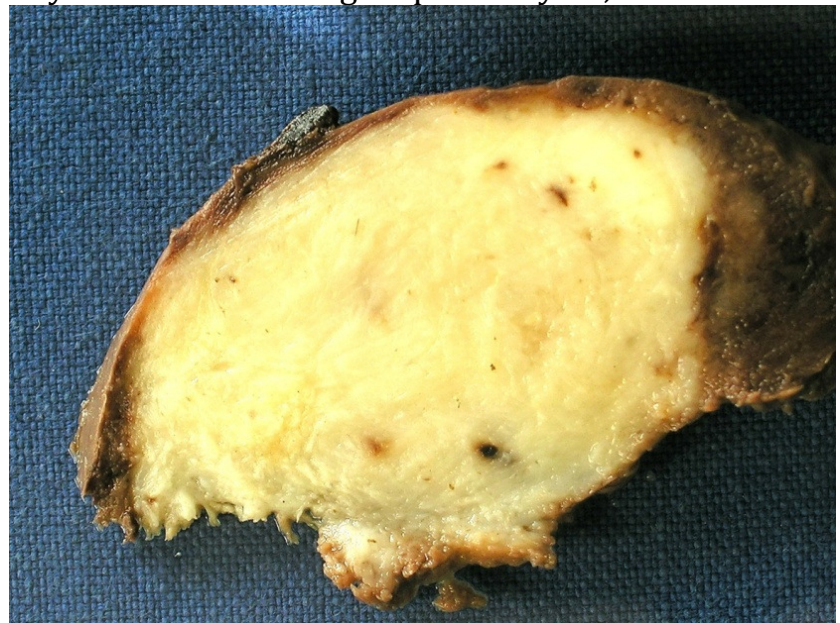

Figure 2. Gross appearance of the lesion: cut gray-white solid, invasive border.

\section{Microscopic Appearance}

Three distinct patterns:

1) Dominant is a loose network of spindle cells, moderate nuclear pleomorphism and hyperchromasia.

2) Sheets and nests of undifferentiated (blastomatous) cells, hyperchromatic nuclei, some with nucleoli. 
3) Scattered glandular structures, cuboidal to columnar epithelium. (fig.3 A-D)
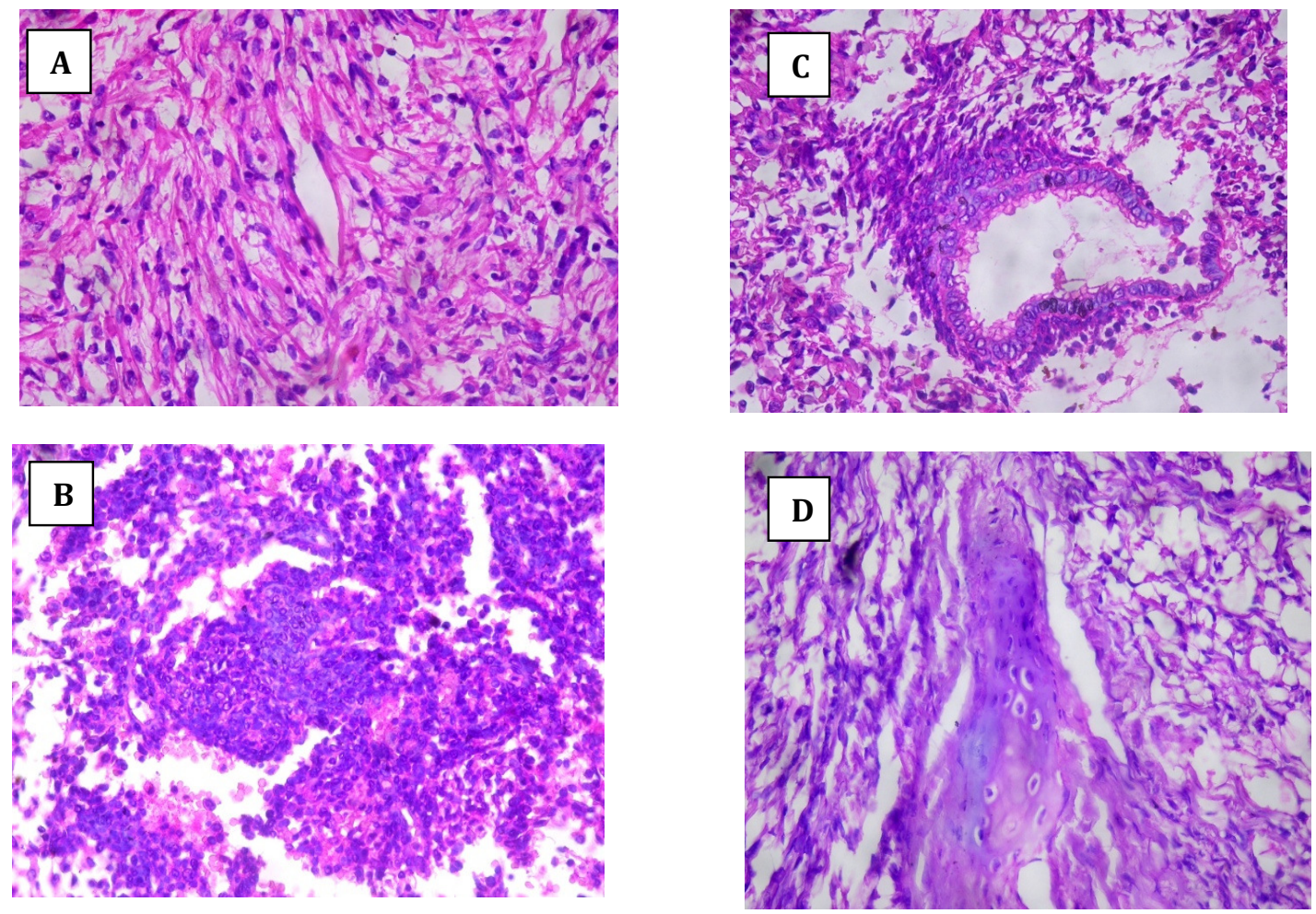

Figure 3. A. loose network of spindle cells, B. Sheets of blastomatous cells with hyperchromatic nuclei, C. Scattered glandular elements, D. entrapped (non-neoplastic?) bronchus-like structures. (all microscopic pictures: hematoxylin-eosin stains, initial magnification 400x.0

\section{Discussion}

Pleuropulmonary blastoma is a primary intrathoracic malignancy that occurs mainly in early childhood. This dysontogenetic neoplasm, an analog to the other unique childhood tumors like Wilms' tumor and neuroblastoma, is classified with the "mesenchymal neoplasms" in the WHO Classification of Lung Tumors ${ }^{17}$. There it is composed of immature mesenchyme, often differentiating toward skeletal muscle, cartilage, fibrous tissue, and sometimes fat, and most often includes epithelium. The mesenchymal elements are regarded as malignant.

Since PPB was recognized as clinicopathologic entity distinct from adult pulmonary blastoma, which is characterized by malignant glands and malignant stroma, the epithelial elements in PPB have been described as benign ${ }^{2}$. In the past, they have been termed pulmonary sarcoma arising in mesenchymal cystic hamartoma, embryonal sarcoma, or rhabdomyosarcoma arising in congenital cystic adenomatoid malformation or bronchogenic cysts ${ }^{3}$. The age onset of presentation was between two weeks to 96 months $^{4}$. Although respiratory difficulty with or without fever is the most common clinical symptom, PPB can present with spontaneous pneumothorax ${ }^{5,6}$, or empyema ${ }^{7,16}$. There are few reports of bilateral $\mathrm{PPB}^{8,9}$. 
A significant feature of patients with PPB is the extraordinary high prevalence of other tumors in close relatives, which has been reported to be as high as $25 \%^{1,4}$. In general, there are no characteristic findings on imaging studies. Dehner ${ }^{10}$ proposed a classification scheme for PPB that divides these lesions into predominantly cystic (type I), cystic and solid (type II), and predominantly solid (type III) types. Each type is characterized by increasing histologic evidence of malignancy ${ }^{10}$. There is a report in which the progression of PPB from type I to type III has been documented over the time ${ }^{11}$.Grossly, cystic tumors are single or multiloculated and may show nodular, thickened walls or pedunculated nodules. Solid tumors are multi lobulated white-gray with focal hemorrhage ${ }^{3}$. Microscopically cystic lesions consist of one or more spaces lined by benign alveolar or ciliated columnar epithelial cells, beneath them, there is a layer of primitive oval and spindled rhabdomyoblasts in a loose or dense fibrovascular stroma. Solid tumors consist of blastomal stromal cells, arranged in alternating bands of compact and loose cells in myxoid matrix. The three pathologic types are correlated with both age at diagnosis and clinical outcome. Type I occurs in infants (median diagnosis age,10 months) in contrast to types II and III (median diagnosis ages, 34 and 44 months, respectively) 4 Type I PPB has been identified in utero ${ }^{18}$. If PPB recurs in an individual patient, the type has often progressed to more advanced disease ${ }^{4,10}$. The diagnosis is made only on histologic evaluation of the excised mass; however, fine-needle aspiration cytology has been used to diagnose it $13,14,15,16$. Immunohistochemical staining mirrors a range of differentiation, with vimentin, histiocytic markers, or myoid antigens being common ${ }^{3,12}$.

The rarity of PPB has allowed only slow elucidation of its clinical features according to prognosis and its response to therapy ${ }^{20}$. The treatment is primarily complete excision of the tumor 21,22, followed by intense chemotherapy ${ }^{23}$. Although there is disagreement in the literature, local radiotherapy also has been applied to PPB ${ }^{1}$. Metastatic spread can also affect the ipsilateral lobes of the lung, the central nervous system including the spinal cord, and skeletal system. The prognosis depends largely on the staging at the time of diagnosis and the grading of the sarcomatous elements, but in general these are aggressive neoplasms with a 5-year survival probability of less than $50 \%$ of the cases with a solid component ${ }^{24}$. Type I PPB is characterized by subtle malignant changes and a good prognosis. Recurrences after type I PPB are usually advanced type II or type III neoplasms with a poor prognosis. It has also been suggested that "extrapulmonary" involvement in PPB, defined as involvement of "the pleura, diaphragm or mediastinum," Indicates a less favorable prognosis ${ }^{19}$.

\section{Referrences}

1. Indolfi P, Casale F, Carli M, Bisogno G, Ninfo V, Cecchetto G, et al. Pleuropulmonary blastoma: management and prognosis of 11 cases. Cancer 2000; 89 (6): 1396-401.

2. Manivel JC, Priest JR, Watterson J, Steiner M, Woods WG, Wick MR, et al. Pleuropulmonary blastoma. The so-called pulmonary blastoma of childhood. Cancer 1988; 62 (8): 1516-26.

3. Hasleton PS. Spencer's pathology of the lung. 5ed, Mc Grow-Hill, 1996; P: 898-1002.

4. Priest JR, McDermott MB, Bhatia S, Watterson J, Manivel JC, Dehner LP. Pleuropulmonary blastoma: a clinicopathologic study of 50 cases. Cancer 1997; 80 (1): 147-61.

5. Guler E, Kutluk MT, Yalcin B, Cila A, Kale G, Buyukpamukcu M. Pleuropulmonary blastoma in a child presenting with pneumothorax. Tumori 2001; 87 (5): 340-2. 
6. Kuzucu A, Soysal O, Yakinci C, Aydin NE. Pleuropulmonary blastoma: report of a case presenting with spontaneous pneumothorax. Eur J Cardiothorac Surg 2001; 19 (2): 22930.

7. Katz DS, Scalzetti EM, Groskin SA, Kohman LJ, Patel LS, Landas S. Pleuropulmonary blastoma simulating an empyema in a young child. J Thorac Imaging 1995:10 (2): 112-6.

8. Picaud JC, Levrey H, Bouvier R, Chappuis JP, Louis D, Frappaz D, et al. Bilateral cystic pleuropulmonary blastoma in early infancy. J Pediatr 2000;136 (6): 834-6.

9. Mott BD, Canver CC, Nazeer T, Buchan A, Ilves R. Staged resection of bilateral pleuropulmonary blastoma in a twomonth old girl. J Cardiovasc Surg (Torino) 2001; 42 (1): 135-7.

10. Dehner LP. Pleuropulmonary blastoma is THE pulmonary blastoma of childhood. Semin Diagn Pathol 1994; 11 (2):144-51.

11. Wright JR Jr. Pleuropulmonary blastoma: A case report documenting transition from type I (cystic) to type III (solid). Cancer 2000; 88 (12): 2853-8.

12. Hachitanda Y, Aoyama C, Sato JK, Shimada H. Pleuropulmonary blastoma in childhood. A tumor of divergent differentiation. Am J Surg Pathol 1993; 17 (4):382-91.

13. Nicol KK, Geisinger KR. The cytomorphology of pleuropulmonary blastoma. Arch Pathol Lab Med 2000;124 (3): 416-8.

14. Drut R, Pollono D. Pleuropulmonary blastoma: diagnosis by fine-needle aspiration cytology: a case report. Diagn Cytopathol 1998; 19 (4): 303-5.

15. Gelven PL, Hopkins MA, Green CA, Harley RA, Wilson MM. Fine-needle aspiration cytology of pleuropulmonary blastoma: case report and review of the literature. Diagn Cytopathol 1997; 16 (4): 336-40.

16. Merriman TE, Beasley SW, Chow CW, Smith PJ, Robertson CF; Pediatric Pulmonology[1996, 22(6):408-411]

17. Dehner LP, Tazelaar HD, Manabe T: Pathology and genetics of tumours of the lung, pleura, thymus and heart, in Travis WD, Brambilla E, Muller-Hermelink HK, et al (eds): World Health Organization Classification of Tumours. Lyon, France, IARC Press, 2004

18. Miniati DN, Chintagumpala M, Langston C, et al: Prenatal presentation and outcome of children with pleuropulmonary blastoma. J Pediatr Surg 41: 66-71, 2006

19. Indolfi $\mathrm{P}$, Casale $\mathrm{F}$, Carli $\mathrm{M}$, et al: Pleuropulmonary blastoma: Management and prognosis of 11 cases. Cancer 89:1396-1401, 2000

20. Romeo C, Impellizzeri P, Grosso M, Vitarelli E, Gentile C. Pleuropulmonary blastoma: long-term survival and literature review. Med Pediatr Oncol 1999; 33 (4): 372-6.

21. Tagge EP, Mulvihill D, Chandler JC, Richardson M, Uflacker R, Othersen HD. Childhood pleuropulmonary blastoma: caution against nonoperative management of congenital lung cysts. J Pediatr Surg 1996; 31 (1): 187-9; discussion 190.

22. Granata C, Gambini C, Carlini C, Repetto P, Torre M, Mazzola C, et al. Pleuropulmonary blastoma. Eur J Pediatr Surg 2001; 11 (4): 271-3.

23. Parsons SK, Fishman SJ, Hoorntje LE, Jaramillo D, Marcus KC, Perez-Atayde AR, et al. Aggressive multimodal treatment of pleuropulmonary blastoma. Ann Thorac Surg 2001; 72 (3): 939-42.

24. Christopher D.M. Fletcher. Diagnostic histopathology of tumors of the lung and pleura. Moran C.A. .Suster S, Chapter 5, Churchill Livingstone. 2000; Vol. 1, p: 171- 208. 